\title{
Qualidade fisiológica e sanitária de sementes de erva-doce (Foeniculum vulgare Mill.) armazenadas
}

\author{
GAMA, J.S.N. ${ }^{1 *}$; BRUNO, R.L.A. ${ }^{2}$; SILVA, K.R.G. ${ }^{2}$; RÊGO, E.R. ${ }^{2}$; PEREIRA FILHO,T.B. ${ }^{2}$; BARBOSA, R.C. ${ }^{2}$; \\ BEZERRA, A.K.D. ${ }^{2}$ \\ ${ }^{1}$ Universidade Federal de Pelotas, Programa de Pós-Graduação em Ciência e Tecnologia de Sementes, CEP: \\ Caixa Postal 354, CEP: 96001-970, Pelotas-Brasil ${ }^{2}$ Universidade Federal da Paraíba, Centro de Ciências Agrárias, \\ CEP: 58397-000, Areia-Brasil *julianasimoes22@yahoo.com.br
}

\begin{abstract}
RESUMO: A incidência de fungos em sementes interfere negativamente o seu potencial fisiológico, podendo ter início no campo, durante o armazenamento ou na pós-colheita. Desta forma o objetivo deste trabalho foi avaliar a qualidade fisiológica e sanitária de sementes de erva-doce armazenadas em diferentes embalagens. O trabalho foi realizado no Laboratório de análise de sementes da UFPB, em Areia-PB. As sementes foram colhidas em plantas tratadas e não tratadas com inseticida Actara, beneficiadas e acondicionadas nas embalagens papel alumínio, saco plástico e vidro. Em seguida, armazenadas em câmara fria durante 315 dias. Inicialmente e a cada 45 dias foram realizados as seguintes determinações e testes: teor de água, emergência de plântulas, primeira contagem de emergência, índice de velocidade de emergência, comprimento e massa seca das plântulas e sanidade das sementes pelo método "blotter-test". Utilizou-se o delineamento inteiramente casualizado, com quatro repetições, os tratamentos foram distribuídos em fatorial $2 \times 3$ $x 8$ (com e sem inseticida, 3 embalagens e 8 períodos de avaliação). Os resultados indicam que a qualidade fisiológica das sementes de erva-doce foi principalmente afetada pelo fungo Alternaria sp., ocorrendo a manutenção da viabilidade das sementes por aproximadamente 95 dias na embalagem de saco plástico; a aplicação do inseticida Actara mantém a qualidade fisiológica das sementes de Foeniculum vulgare no armazenamento.
\end{abstract}

Palavras-chave: deterioração, embalagem, Alternaria sp.

ABSTRACT: Physiological and sanitary quality of fennel seeds stored. The fungi incidence in seeds affect negatively their physiological potential may begin in the field, during storage or in post-harvest. The objective was to evaluate the sanitary quality of fennel seeds stored in packagings differents. The study was conducted in laboratory analysis of seeds of UFPB, in Areia-PB. Seeds were harvested in experimental field with plants treated and untreated with insecticide Actara, processed and packed in aluminum foil, plastic bag and glass and stored in cold chamber during 315 days. Initially and every 45 days were performed the following tests and determinations: water content, seedling emergence, first count of emergency, emergency speed index, length and seedling dry mass and seed health by the "blotter-test." We used a completely randomized design with four replications, the treatments were distributed in a factorial $2 \times 3 \times 8$. The results indicated that the physiological quality of fennel seeds was negatively affected by the fungus Alternaria sp., occurring at maintaining the viability of seeds for about 95 days in the plastic bag packaging; the application of the insecticide Actara keeps the physiological quality of seeds of Foeniculum vulgare in storage.

Key words: deterioration, packing, Alternaria sp.

\section{INTRODUÇÃO}

A erva-doce (Foeniculum vulgare Mill.) é uma espécie pertencente à família Apiaceae, bastante utilizada no Brasil por apresentar propriedades aromáticas, condimentares e medicinais (Choi \&
Hwang, 2004; Simões et al., 2004). De acordo com Lorenzi \& Matos (2008), esta espécie possui diversas propriedades farmacêuticas, como inseticida, antifúngica, estimulante digestivo e estrogênica. Ela

Recebido para publicação: setembro de 2011

Aceito para publicação: março de 2012

Rev. Bras. PI. Med., Botucatu, v.14, n.esp., p.175-182, 2012. 
é usada principalmente no tratamento de problemas digestivos, cólicas e distúrbios ginecológicos (Kwon et al., 2002) e também bastante utilizada na indústria cosmética, devido à presença de óleo essencial rico em vários princípios ativos com atividade biológica (Sousa et al., 2005).

Nos últimos anos a produção de sementes de erva-doce vem sendo inviabilizada em função da alta incidência do pulgão Hyadaphis foeniculi (Passerini, 1860), este inseto ataca principalmente as inflorescências da planta, sugando a seiva e depauperando as sementes (Wanderley \& Marçal, 1998). O controle é realizado principalmente por aplicações de inseticidas, sendo o acefato, deltametrina, dimetoato, metamidofós, paratiom metílico e pirimicarbe, os principais produtos empregados pelos agricultores (Andrei, 1999).

Problemas advindos da utilização indiscriminada desses agrotóxicos, como a contaminação do solo e da água e a intoxicação dos produtores, havendo vários relatos de problemas de saúde que, segundo os agricultores, estariam relacionados à aplicação desses inseticidas de forma crescente (Nunes et al., 2007). Além disso, por ser muito utilizada na produção de medicamentos naturais, culinária e indústria cosmética, o uso de sementes de erva-doce contaminadas por agrotóxicos pode trazer sérios riscos para a saúde da população em geral (Azevedo, 2009).

A qualidade da semente é fator de extrema importância para que se obtenha a produtividade esperada, e o armazenamento é prática fundamental para o controle da qualidade fisiológica da semente, sendo um método por meio do qual, pode-se preservar a viabilidade das sementes e manter 0 vigor em nível razoável no período compreendido entre o plantio e a colheita (Azevedo et al., 2003). O nível de deterioração em sementes armazenadas depende das condições do lote por ocasião do início da armazenagem e do controle dos fatores ambientais durante essa fase (Freitas et al., 2000). Outro fator importante a ser considerado é a incidência de fungos no armazenamento (Lacerda et al., 2003), constituindo-se, juntamente com os insetos, as principais causas de deterioração e perdas (Santos, 2006).

O tipo de embalagem em que as sementes são armazenadas também assume papel importante (Torres et al., 2002). Segundo Carvalho \& Nakagawa (2000), na tomada de decisão para a escolha da mesma, devem ser consideradas também a modalidade de comercialização, disponibilidade e as características mecânicas das embalagens.

Por este motivo, objetivou-se com este trabalho avaliar a qualidade fisiológica e sanitária das sementes de erva-doce tratadas e não tratadas com inseticida armazenadas em diferentes embalagens.

\section{MATERIAL E MÉTODO}

A cultura da erva-doce ( $F$. vulgare Mill.) foi implantada em campo experimental localizado no município de Lagoa Seca-PB (7010'15" S e 3551'14" W), com clima do tipo As' tropical úmido e Bsh quente com chuvas de verão, segundo a classificação de Köppen. As precipitações pluviais atingem uma média anual de $990 \mathrm{~mm}$ e temperatura média anual entre 22 e $26^{\circ} \mathrm{C}$. Semanalmente aplicava-se em algumas parcelas o inseticida Actara na proporção de 1:1 (20 $\mathrm{g}$ de inseticida/20 litros de água), para o controle do pulgão Hyadaphis foeniculi, caracterizando assim, dois tratamentos em campo: T1 = erva-doce tratada com inseticida; T2 = erva-doce não tratada com inseticida.

O armazenamento das sementes foi conduzido no Laboratório de Análise de Sementes (LAS) do Centro de Ciências Agrárias (CCA) da Universidade Federal da Paraíba (UFPB), Areia-PB. As sementes foram acondicionadas nas embalagens: papel alumínio, saco plástico e vidro. Em seguida estas embalagens foram mantidas em câmara-fria $\left(10^{\circ} \mathrm{C}\right.$ e $60 \%$ UR) durante 315 dias, totalizando-se seis tratamentos (sementes tratadas e não tratadas com inseticida $x$ três embalagens). Inicialmente e a cada 45 dias as sementes de erva-doce foram avaliadas quanto a sua qualidade fisiológica e sanitária por meio das seguintes determinações e testes:

Teor de água - utilizaram-se duas subamostras contendo em média $0,200 \mathrm{~g}$ de sementes em cápsulas de alumínio, colocadas em estufa a $105 \pm 3^{\circ} \mathrm{C}$, por 24 horas e os resultados expressos em porcentagem.

Emergência de plântulas em ambiente protegido - na avaliação da emergência foram utilizadas 400 sementes, as quais foram divididas em quatro repetições de 100, semeadas em bandejas contendo areia autoclavada. As contagens das plântulas emersas foram realizadas diariamente prolongando-se até o 15 dia após a semeadura, período em que ocorreu a estabilização, considerando normais àquelas com características condizentes com as prescritas pelas RAS (Brasil, 2009) e os resultados foram expressos em porcentagem (Nakagawa, 1999).

Primeira contagem de emergência - Para a execução deste teste foi utilizado o mesmo material do teste de emergência, sendo realizada a leitura das plântulas emersas no 10 ㅇa dia após a semeadura, momento em que se obteve um estande de plântulas inicialmente homogêneo.

Índice de velocidade de emergência (IVE) - foi determinado registrando-se diariamente o número de plântulas emersas a partir do $5 \circ$ até o $15 \circ$ dia após a semeadura e calculado pela fórmula proposta por Maguire (1962).

Comprimento de plântulas - ao final do

Rev. Bras. PI. Med., Botucatu, v.14, n.esp., p.175-182, 2012. 
teste de emergência, as plântulas normais de cada repetição foram utilizadas para se avaliar o comprimento (raiz até a inserção dos cotilédones), com o auxílio de régua graduada em centímetros, sendo os resultados expressos em centímetros por plântula.

Massa seca de plântulas - as plântulas provenientes da avaliação do comprimento, foram colocadas em sacos de papel tipo kraft e acondicionadas em estufa com circulação de ar forçada, regulada a $65^{\circ} \mathrm{C}$, onde permaneceram até atingir massa constante. Em seguida, foram pesadas em balança analítica com precisão de $0,0001 \mathrm{~g}$, sendo os resultados expressos em gramas por plântula (Nakagawa, 1999).

Teste de sanidade - determinado no início e em cada período do armazenamento, utilizando-se o método do "blotter-test" (Neergaard, 1979). Foram utilizadas cinco repetições de 20 sementes, colocadas no interior de placas de Petri contendo duas folhas de papel filtro, previamente umedecidas com água destilada e esterilizada. Em seguida as placas foram levadas a uma sala com temperatura de $24 \pm 2^{\circ} \mathrm{C}$, permanecendo incubadas por oito dias, com luzes de frequência próxima a ultravioleta e fotoperíodo de 12 horas. Após este período foram realizadas a identificação e contagem dos fungos associados às sementes, com auxílio de microscópio estereoscópico. Os resultados foram expressos em porcentagem de incidência de fungos por repetição.

O delineamento experimental utilizado foi inteiramente ao acaso, com os tratamentos dispostos em esquema fatorial $(2 \times 3 \times 8)$, representados pelos tratamentos em campo (com e sem aplicação de inseticida) três embalagens (papel alumínio, saco plástico e vidro) e oito períodos de armazenamento $(0,45,90,135,180,225,270$ e 315 dias $)$. Os dados foram submetidos à análise de variância, para os tratamentos qualitativos as médias foram comparadas pelo teste de Tukey a $5 \%$ de probabilidade e para o fator quantitativo foi realizada análise de regressão polinomial, selecionando-se os modelos significativos $(F \leq 0,05)$, com $R 2 \geq 60 \%$.

\section{RESULTADO E DISCUSSÃO}

De acordo com os resultados obtidos na análise de variância (Tabela 1) observa-se que a interação tripla inseticida*embalagem*período (INSET $\left.{ }^{*} E M{ }^{*} P E\right)$ foi significativa em todas as variáveis testadas. O mesmo ocorreu com as interações duplas inseticida*embalagens (INSET* EMB); inseticida*período (INSET*PE) e embalagem* período (EMB*PE). No entanto, ao desdobrar o fator inseticida em relação aos períodos de armazenamento, verifica-se que apenas a variável comprimento de plântulas se ajustou ao modelo de regressão, independentemente da aplicação ou não do inseticida. Quanto à embalagem, em relação aos períodos de armazenamento, constatou-se que o comprimento de plântulas se ajustou ao modelo de regressão nas embalagens papel alumínio e vidro, também houve ajuste para massa seca de plântulas na embalagem saco plástico.

Por meio do teste de médias, referente ao desdobramento da interação EMB/INSET, verifica-se que, não houve diferença estatística entre as embalagens utilizadas em nenhuma das variáveis testadas. Porém, a aplicação do inseticida proporcionou diferenças estatísticas significativas nas variáveis: índice de velocidade de emergência (IVE), porcentagem de emergência, primeira contagem de emergência e comprimento de plântulas, proporcionado acréscimo em todos os valores, independente da embalagem. Entretanto, o uso do inseticida não afetou o teor de massa seca das plântulas (Tabela 2).

Em sementes de girassol tratadas com inseticidas e fungicidas, armazenadas por 90 dias, Grisi et al. (2009) constataram que os valores de IVE e emergência em areia reduziram ao longo dos períodos avaliados (0, 45 e 90 dias); as sementes tratadas com inseticida Thiamethoxan e Thiamethoxan + Fludioxonil obtiveram menores valores médios de emergência em relação às sementes sem inseticidas e tratadas com Fipronil.

Com relação ao desenvolvimento inicial das plântulas de erva-doce oriundas do tratamento com inseticida (Figura 1), observa-se que o comprimento máximo foi obtido no período de 90 dias $(10,72 \mathrm{~cm})$ e as plântulas oriundas do tratamento sem inseticida aos 95 dias $(10,33 \mathrm{~cm})$, seguindo de decréscimos nos períodos subsequentes do armazenamento. Percebe-se que o uso do inseticida proporcionou o maior valor de comprimento de plântulas em menor tempo. Provavelmente, pelo fato do inseticida actara ter combatido eficientemente os pulgões que danificavam as inflorescências, sugando a seiva, consequentemente, acarretando na formação de sementes menos vigorosas que originaram também plântulas com menor vigor.

Em plântulas de girassol os dados de comprimento da parte aérea e do sistema radicular foram influenciados apenas pelo tempo de armazenamento. Grisi et al. (2009) observaram que as sementes armazenadas por 90 dias obtiveram melhor desenvolvimento do comprimento da raiz e da parte aérea. Este mesmo comportamento foi verificado por Gotardo (2003), em que os dados referentes ao comprimento da raiz e da parte aérea apresentaram valores inicialmente semelhantes entre si, tanto nas avaliações realizadas com amostras de sementes tratadas e não tratadas.

Em relação às embalagens utilizadas, verifica-se que apenas o papel alumínio e o vidro se 
TABELA 1. Resumo da análise de variância das variáveis (índice de velocidade de emergência - IVE; porcentagem de emergência - E; primeira contagem de emergência - PCE; comprimento de plântulas - CP e massa seca de plântulas - MSP) avaliadas em sementes de Foeniculum vulgare Mill. durante o armazenamento. (Areia-PB, 2011).

\begin{tabular}{|c|c|c|c|c|c|}
\hline \multirow[b]{2}{*}{ FV } & \multicolumn{4}{|c|}{ Quadrados médios } & \multirow[b]{2}{*}{ MSP } \\
\hline & IVE & $\mathbf{E}$ & PCE & CP & \\
\hline Inseticida & $239,2^{* *}$ & $12464^{* *}$ & $5536,2^{* \star}$ & $9,6^{* *}$ & $4,3^{* *}$ \\
\hline Embalagem & $6,62^{* *}$ & $169,9^{* *}$ & $222,2^{* *}$ & $3,8^{* *}$ & $1,2^{* *}$ \\
\hline Período & $179,8^{* *}$ & $2348,4^{* *}$ & $7717,5^{\star \star}$ & $153^{* *}$ & $12,6^{* *}$ \\
\hline INSET*EMB & $10,7^{* *}$ & $117,6^{*}$ & $511,8^{* *}$ & $0,8^{* *}$ & $0,5^{* *}$ \\
\hline Sem/INSET*PE & $3,8^{* *}$ & $313^{* *}$ & $422,7^{* *}$ & $1,2^{* *}$ & $0,6^{* *}$ \\
\hline Efeito linear & $0,03 \mathrm{NS}$ & 203,3 NS & 1258,7 Ns & $72,5^{*}$ & $3,6 \mathrm{NS}$ \\
\hline Efeito quadratic & $89,5 \mathrm{NS}$ & $602,5 \mathrm{NS}$ & 1533 NS & $77^{*}$ & $0,0 N N S$ \\
\hline Com/INSET*PE & $3,8^{* *}$ & $313^{* *}$ & $422,7^{* *}$ & $1,2^{* *}$ & $0,6^{* *}$ \\
\hline Efeito linear & $8,4 \mathrm{NS}$ & $13,7 \mathrm{NS}$ & $5493,3 \mathrm{NS}$ & $74,2^{*}$ & $7,5 \mathrm{Ns}$ \\
\hline Efeito quadratic & $87,2^{\mathrm{NS}}$ & $684 \mathrm{NS}$ & $1568,5 \mathrm{NS}$ & $72,4^{*}$ & $0,02^{\mathrm{NS}}$ \\
\hline EMB*PE & $10^{* *}$ & $216,3^{* *}$ & $192,7^{* *}$ & $5,9^{* *}$ & $1,4^{* *}$ \\
\hline \multicolumn{6}{|l|}{ EMBP. aluminio ${ }^{*} \mathrm{PE}$} \\
\hline Efeito linear & $15,7 \mathrm{NS}$ & 203,3 NS & $1258,7 \mathrm{NS}$ & $72,5^{*}$ & $3,6 \mathrm{NS}$ \\
\hline Efeito quadratic & $60,6 \mathrm{NS}$ & $602,5^{\mathrm{NS}}$ & $1533^{N S}$ & $77^{*}$ & $0,0 \mathrm{NS}$ \\
\hline \multicolumn{6}{|l|}{ EMBS. plástico $^{*} \mathrm{PE}$} \\
\hline Efeito linear & $1,3 \mathrm{Ns}$ & $5,2^{\mathrm{NS}}$ & $2696^{N S}$ & $78,1 \mathrm{NS}$ & $8,3^{*}$ \\
\hline Efeito quadratic & $130,7^{\mathrm{NS}}$ & $1549,5^{\mathrm{NS}}$ & $2139,2^{\mathrm{NS}}$ & $78 N S$ & $0,5 \mathrm{NS}$ \\
\hline \multicolumn{6}{|l|}{$\mathrm{EMB}_{\text {Vidro }}{ }^{*} \mathrm{PE}$} \\
\hline Efeito linear & $0,2^{\text {NS }}$ & $166^{N S}$ & $3094,3 N S$ & $63,6 \mathrm{NS}$ & $1,7 \mathrm{NS}$ \\
\hline Efeito quadratic & $80,7 \mathrm{NS}$ & 418 NS & $1591 N S$ & $75,2^{*}$ & $0,0 \mathrm{NS}$ \\
\hline INSET*EMB*PE & $6,6^{* *}$ & $311,1^{* *}$ & $264,3^{* *}$ & $3,8^{* *}$ & $0,3^{* *}$ \\
\hline
\end{tabular}

Significativo a $1 \%\left({ }^{* *}\right)$ e a $5 \%\left({ }^{*}\right)$; NS Não significativo.

ajustaram ao modelo de regressão polinomial. $\mathrm{Na}$ Figura 2, observa-se que as sementes de erva-doce quando armazenadas em papel alumínio os maiores comprimentos de plântulas foram atingidos aos 86 dias $(10,32 \mathrm{~cm})$ e na embalagem vidro aos 150 dias $(11,73 \mathrm{~cm})$ de armazenamento. Contudo, a embalagem de vidro manteve ainda maiores valores nos períodos finais do armazenamento em relação ao papel alumínio. Guedes et al. (2010) detectaram os maiores comprimentos de plântulas de Amburana cearensis (Allemão) A.C.Sm. quando as sementes foram embaladas em papel alumínio.

Em relação à qualidade sanitária das sementes de erva-doce constatou-se a incidência dos fungos Alternaria sp., Aspergillus sp. e Cladosporium sp., com predominância do fungo Alternaria sp., independentemente das plantas estarem tratadas ou não com inseticida. Em uma análise global, verificase que o papel alumínio proporcionou maiores incidências dos fungos acima citados nas sementes armazenadas, seguido das embalagens saco plástico e vidro (Tabela 3).

As espécies Alternaria alternata (Fr.) Keissl e A. dauci (Kuhn) Groves e Skolko estão frequentemente associadas a sementes de apiáceas. Segundo Reis et al. (2006), o fungo $A$. dauci pode ser destrutivo a cultura da cenoura e do coentro, além disso, é comprovadamente veiculado e transmitido eficientemente por sementes dessas espécies. A presença de patógenos nas sementes, independentemente da transmissibilidade, pode afetar o vigor e o rendimento em campo (Luz, 2003).

$\mathrm{Na}$ Tabela 4 verifica-se aumento na porcentagem de incidência dos fungos até os 180 
TABELA 2. Dados médios para as variáveis (índice de velocidade de emergência - IVE; porcentagem de emergência E; primeira contagem de emergência - PCE; comprimento de plântulas - CP e massa seca de plântulas - MSP) avaliadas em sementes de Foeniculum vulgare Mill. durante o armazenamento. (Areia-PB, 2011).

\begin{tabular}{|c|c|c|c|c|}
\hline Tratamentos & Papel alumínio & Saco plástico & & Vidro \\
\hline & & IVE & & \\
\hline Com inseticida & $10,55 \mathrm{Aa}$ & $10,85 \mathrm{Aa}$ & & $10,85 \mathrm{Aa}$ \\
\hline Sem inseticida & $7,72 \mathrm{Ab}$ & $7,72 \mathrm{Ab}$ & & $7,72 \mathrm{Ab}$ \\
\hline \multirow[t]{2}{*}{ DMS } & & $0,56 \rightarrow$ & 0,50 & $\uparrow$ \\
\hline & \multicolumn{4}{|c|}{ Emergência (\%) } \\
\hline Com inseticida & $75 \mathrm{Aa}$ & $75 \mathrm{Aa}$ & & $75 \mathrm{Aa}$ \\
\hline Sem inseticida & $59,25 \mathrm{Ab}$ & $59,25 \mathrm{Ab}$ & & $57 \mathrm{Ab}$ \\
\hline DMS $\quad 4,37$ & & & & \\
\hline
\end{tabular}

\begin{tabular}{|c|c|c|c|c|c|}
\hline \multirow[b]{2}{*}{ Com inseticida } & \multicolumn{5}{|c|}{ Primeira contagem de emergência (\%) } \\
\hline & $64,75 \mathrm{Aa}$ & $64,75 \mathrm{Aa}$ & & & $64,75 \mathrm{Aa}$ \\
\hline Sem inseticida & $41,75 \mathrm{Ab}$ & $42,5 \mathrm{Ab}$ & & & $41,75 \mathrm{Ab}$ \\
\hline \multirow[t]{2}{*}{ DMS } & & $3,74 \rightarrow$ & 3,30 & $\uparrow$ & \\
\hline & \multicolumn{5}{|c|}{ Comprimento de plântulas $(\mathrm{cm})$} \\
\hline Com inseticida & $8,78 \mathrm{Aa}$ & $8,79 \mathrm{Aa}$ & & & $8,79 \mathrm{Aa}$ \\
\hline Sem inseticida & $8,32 \mathrm{Ab}$ & $8,32 \mathrm{Ab}$ & & & $8,32 \mathrm{Ab}$ \\
\hline \multirow[t]{2}{*}{ DMS } & & $0,40 \rightarrow$ & 0,36 & $\uparrow$ & \\
\hline & \multicolumn{5}{|c|}{ Massa seca de plântulas (mg) } \\
\hline Com inseticida & $4,75 \mathrm{Aa}$ & $4,75 \mathrm{Aa}$ & & & $4,75 \mathrm{Aa}$ \\
\hline Sem inseticida & $4,5 \mathrm{Aa}$ & $4,5 \mathrm{Aa}$ & & & $4,5 \mathrm{Aa}$ \\
\hline$\overline{D M S}$ & & $0,48 \rightarrow$ & 0,51 & $\uparrow$ & \\
\hline
\end{tabular}

Médias seguidas pelas mesmas letras maiúsculas nas linhas e minúsculas nas colunas, não diferem estatisticamente entre si pelo teste de Tukey a $5 \%$ de probabilidade. Valores do DMS na horizontal $(\rightarrow)$ para embalagens e na vertical $(\uparrow)$ para inseticida.

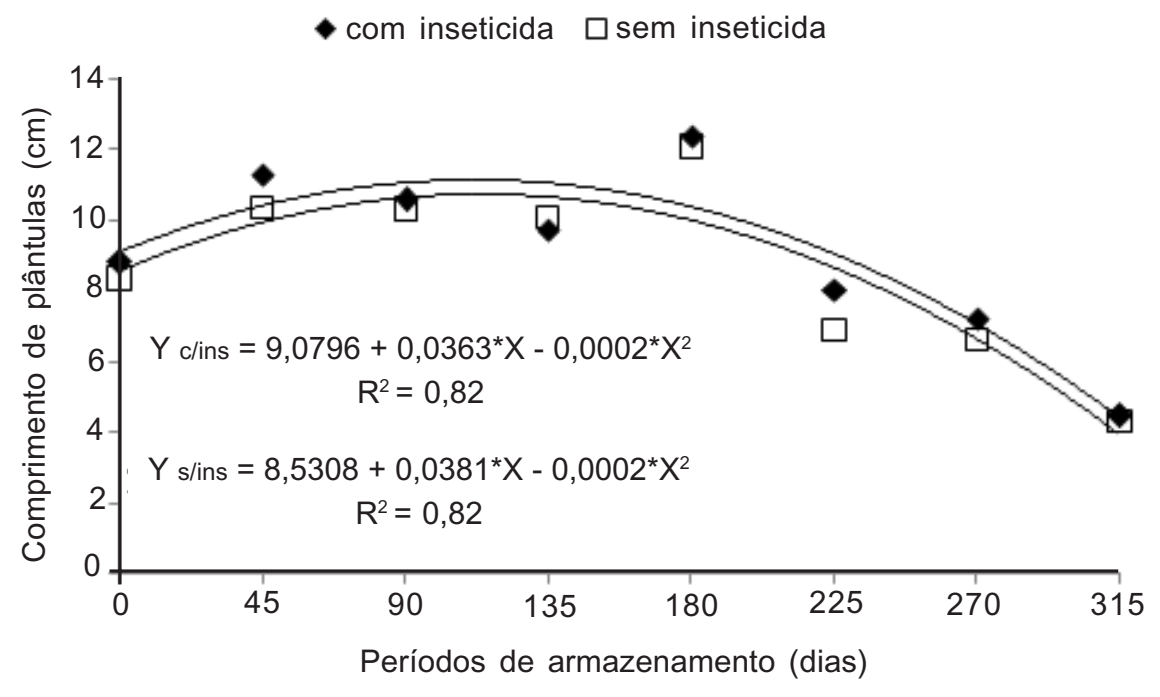

FIGURA 1. Comprimento de plântulas de Foeniculum vulgare Mill. oriundas de sementes de plantas tratadas (c/ins) e não tratadas com inseticida (s/ins) durante o armazenamento. 
papel alumínio ᄃ vidro

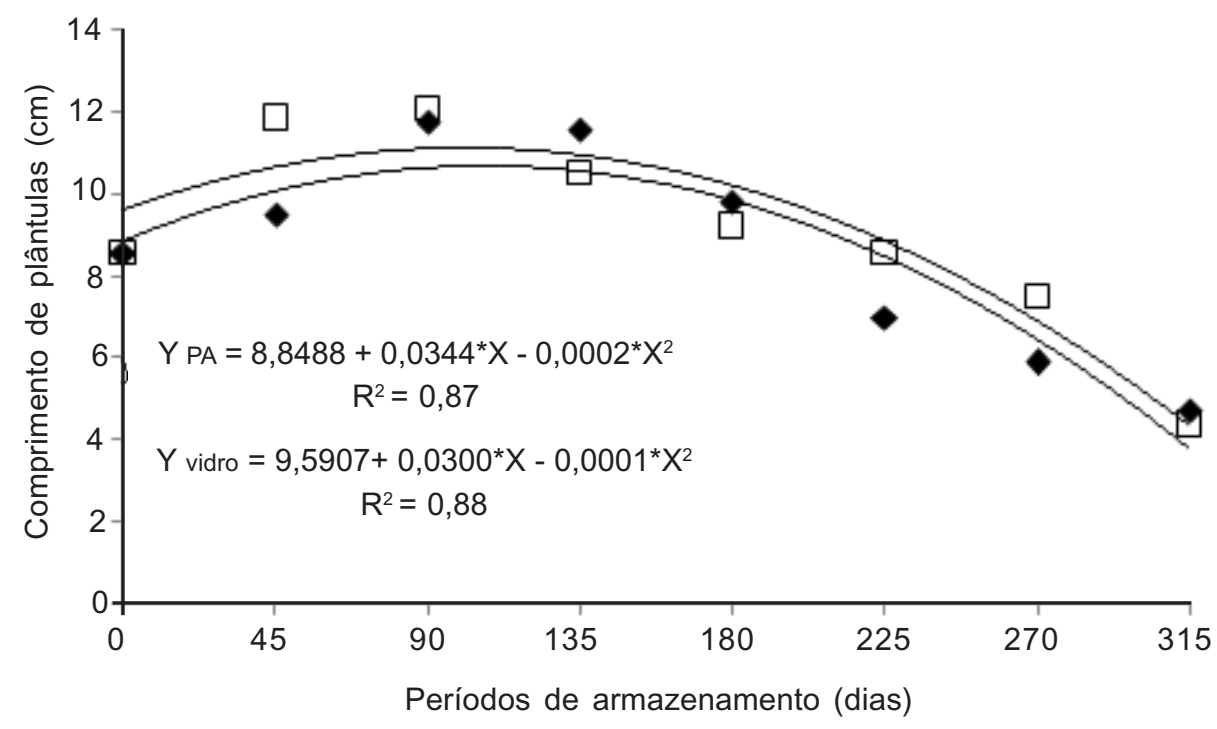

FIGURA 2. Comprimento de plântulas de Foeniculum vulgare Mill. oriundas de sementes armazenadas em diferentes embalagens.

TABELA 3. Dados médios referentes à porcentagem de infestação de fungos nas sementes de Foeniculum vulgare Mill. oriundas de plantas tratadas (C/I) e não tratadas (S/I) com inseticida, armazenadas em diferentes embalagens. (Areia-PB, 2011).

\begin{tabular}{|c|c|c|c|c|c|c|}
\hline \multirow{3}{*}{ Embalagem } & \multicolumn{6}{|c|}{ Porcentagem de incidência de fungos } \\
\hline & \multicolumn{2}{|c|}{ Alternaria sp. } & \multirow{2}{*}{$\frac{\text { Aspergillus sp. }}{\mathrm{C} / \mathrm{l}}$} & \multicolumn{2}{|c|}{ Cladosporium sp. } & \multirow[b]{2}{*}{$\mathrm{S} / \mathrm{l}$} \\
\hline & $\mathrm{C} / \mathrm{l}$ & $S / l$ & & $S / l$ & $\mathrm{C} / \mathrm{l}$ & \\
\hline Papel alumínio & 0,64 Aab & $0,91 \mathrm{Aa}$ & $0,27 \mathrm{Ba}$ & $0,24 \mathrm{Ca}$ & $0,28 \mathrm{Ba}$ & $0,59 \mathrm{Ba}$ \\
\hline Saco plastic & $0,71 \mathrm{Aa}$ & $0,76 \mathrm{Ab}$ & $0,25 \mathrm{Ba}$ & $0,22 \mathrm{Ba}$ & $0,24 \mathrm{Ba}$ & $0,32 \mathrm{Bb}$ \\
\hline Vidro & $0,59 \mathrm{Ab}$ & $0,53 \mathrm{Ac}$ & $0,24 \mathrm{Ba}$ & $0,22 \mathrm{Ba}$ & $0,29 \mathrm{Ba}$ & $0,29 \mathrm{Bb}$ \\
\hline DMS & $\mathrm{C} / \mathrm{I}=0,10 \rightarrow$ & $0,10 \uparrow$ & $S / 1=$ & $11 \rightarrow$ & & \\
\hline
\end{tabular}

Médias seguidas de mesma letra maiúscula na linha e minúscula na coluna, não diferem estatisticamente pelo teste de Tukey a $5 \%$ de probabilidade. Valores do DMS na horizontal $\leftrightarrow$ ) para inseticida e na vertical $(\uparrow)$ para embalagens.

dias de armazenamento, seguido de redução drástica aos 225 dias, havendo leve aumento nos últimos períodos. Possivelmente, essa oscilação esteja relacionada a forte competição entre as populações dos fungos, as quais vinham de crescimento contínuo nos períodos anteriores, aumentando assim a competição por espaço e alimento.

Horn (2005) explica que normalmente os fatores ambientais e os aspectos fisiológicos das espécies ou isolados de patógenos influenciam a sua competição por espaço e nutrientes. Possivelmente, esta competição diminuiu a população dos fungos associados às sementes ou até mesmo a ação patogênica.
Pedroso et al. (2010), estudando a relação da Alternaria dauci com sementes de salsa, constataram que o tratamento contendo sementes inoculadas com este fungo reduziu drasticamente a porcentagem de plântulas normais, comprovando que esse patógeno interfere no potencial fisiológico das mesmas. Nascimento et al. (2006) também observaram a incidência de $A$. dauci durante o armazenamento de sementes de coentro.

Dessa forma, pode-se concluir que a qualidade fisiológica das sementes de erva-doce foi principalmente afetada pelo fungo Alternaria sp.; a aplicação do inseticida Actara mantém a qualidade fisiológica das sementes de $F$. vulgare no armazenamento. 
TABELA 4. Dados médios referentes à porcentagem de incidência de fungos nas sementes de Foeniculum vulgare Mill. oriundas de plantas tratadas (C/I) e não tratadas (S/I), durante o armazenamento. (Areia-PB, 2011).

\begin{tabular}{lcccccc}
\hline \multicolumn{7}{c}{ Porcentagem de incidência de fungos } \\
\hline Períodos & Alternaria sp. & Aspergillus sp. & \multicolumn{1}{c}{ Cladosporium sp. } \\
\hline (dias) & $\mathrm{C} / \mathrm{l}$ & $\mathrm{S} / \mathrm{l}$ & $\mathrm{C} / \mathrm{l}$ & $\mathrm{S} / \mathrm{l}$ & $\mathrm{C} / \mathrm{l}$ & $\mathrm{S} / \mathrm{l}$ \\
0 & $0,67 \mathrm{Abc}$ & $0,73 \mathrm{Ac}$ & $0,22 \mathrm{Bb}$ & $0,22 \mathrm{Cb}$ & $0,22 \mathrm{Bc}$ & $0,55 \mathrm{Bb}$ \\
45 & $0,68 \mathrm{Abc}$ & $0,72 \mathrm{Ac}$ & $0,23 \mathrm{Bb}$ & $0,23 \mathrm{Bb}$ & $0,27 \mathrm{Bc}$ & $0,28 \mathrm{Bde}$ \\
90 & $0,73 \mathrm{Ab}$ & $0,72 \mathrm{Ac}$ & $0,23 \mathrm{Bb}$ & $0,25 \mathrm{Bb}$ & $0,23 \mathrm{Bc}$ & $0,23 \mathrm{Be}$ \\
135 & $0,71 \mathrm{Abc}$ & $0,71 \mathrm{Ac}$ & $0,23 \mathrm{Bb}$ & $0,23 \mathrm{Cb}$ & $0,28 \mathrm{Bc}$ & $0,34 \mathrm{Bcd}$ \\
180 & $1,30 \mathrm{Aa}$ & $1,25 \mathrm{Aa}$ & $0,47 \mathrm{Ca}$ & $0,46 \mathrm{Ca}$ & $0,63 \mathrm{Ba}$ & $0,71 \mathrm{Ba}$ \\
225 & $0 \mathrm{Ad}$ & $0 \mathrm{Ad}$ & $0 \mathrm{Ac}$ & $0 \mathrm{Ac}$ & $0 \mathrm{Ad}$ & $0 \mathrm{Af}$ \\
270 & $0,68 \mathrm{Abc}$ & $0,83 \mathrm{Ab}$ & $0,24 \mathrm{Cb}$ & $0,23 \mathrm{Cb}$ & $0,44 \mathrm{Bb}$ & $0,36 \mathrm{Bcd}$ \\
315 & $0,64 \mathrm{Ac}$ & $0,73 \mathrm{Ac}$ & $0,26 \mathrm{Bb}$ & $0,23 \mathrm{Cb}$ & $0,27 \mathrm{Bc}$ & $0,40 \mathrm{Bc}$ \\
\hline DMS & \multicolumn{7}{c}{$\mathrm{C} / \mathrm{l}=0,07 \rightarrow$} & $0,08 \uparrow$ & $\mathrm{S} / \mathrm{l}=0,07 \rightarrow \quad 0,02 \uparrow$ & \\
\hline
\end{tabular}

Médias seguidas de mesma letra maiúscula na linha e minúscula na coluna, não diferem estatisticamente pelo teste de Tukey a $5 \%$ de probabilidade. Valores do DMS na horizontal $(\rightarrow)$ para inseticida e na vertical ( $\uparrow$ ) para períodos.

\section{AGRADECIMENTO}

Ao Laboratório de Fitopatologia do Centro de Ciências Agrárias - UFPB, pela estrutura cedida na realização dos testes de sanidade.

\section{REFERÊNCIA}

ANDREI, E. Compêndio de defensivos agrícolas. 6.ed. São Paulo: Andrei, 1999. 676p.

AZEVEDO, C.F. Qualidade de sementes e morfoanatomia de plântulas de Foeniculum vulgare Mill. oriundas de sistemas de consórcio. 2009. 144p. Dissertação (Mestrado em Agronomia) - Universidade Federal da Paraíba, Areia.

AZEVEDO, M.R.Q.A. et al. Influência das embalagens e condições de armazenamento no vigor de sementes de gergelim. Revista Brasileira de Engenharia Agrícola e Ambiental, v.7, n.3, p.519-24, 2003.

BRASIL, Ministério da Agricultura e Reforma Agrária. Regras para Análise de sementes. Brasília: SNDP/ DNDV/CLAV, 2009. 395p.

CARVALHO, N.M.; NAKAGAWA, J. Sementes: ciência e produção. 4.ed. Jaboticabal: Funep, 2000. 588p.

CHOI, E.M.; HWANG, J.K. Antiinflammatory, analgesic and antioxidant activities of the fruit of Foeniculum vulgare. Fitoterapia, v.75, n.6, p.557-65, 2004.

FREITAS, R.A. et al. Qualidade fisiológica e sanitária de sementes de algodão durante o armazenamento. Revista Brasileira de Sementes, v.22, n.2, p.94-101, 2000.

GRISI, P.U. et al. Qualidade das sementes de girassol tratadas com inseticidas e fungicidas. Bioscience Journal, v.25, n.4, p.28-36, 2009.

GUEDES, R.S. et al. Qualidade fisiológica de sementes armazenadas de Amburana cearensis (Allemão) A.C. Smith. Semina: Ciências Agrárias, v.31, n.2, p.331-42, 2010. HORN, B.W. Colonization of wouded peanut seeds by soil fungi: selectivity for species from Aspergillus section Flavi. Mycologia, v.97, p.202-17, 2005.

KWON, Y.S. et al. Antimicrobial constituents of Foeniculum vulgare. Archibes of Pharmacal Research, v.25, n.2, p.154-7, 2002.

LACERDA, A.L.C. et al. Armazenamento de sementes de soja dessecadas e avaliação da qualidade fisiológica, bioquímica e sanitária. Revista Brasileira de Sementes, v.25, n.2, p.97-105, 2003.

LORENZI, H.; MATOS, F.J.A. Plantas medicinais no Brasil: nativas e exóticas. 2.ed. Nova Odessa: Instituto Plantarum, 2008.

LUZ, W.C. Combinação dos tratamentos biológico e químico de sementes de milho. Fitopatologia Brasileira, v.28, p.37-40, 2003.

MAGUIRE, J.D. Speed of germination-aid seedling emergence and vigor. Crop Science, v.2, n.2, p.176-7, 1962.

NAKAGAWA, J. Testes de vigor baseados no desempenho de plântulas. In: KRZYZANOWSKI, F.C.; VIEIRA, R.D.; FRANÇA NETO, J.B. (Eds.). Vigor de sementes: conceitos e testes. Londrina: ABRATES. 1999. cap.2, p.1-24.

NASCIMENTO, W.M. et al. Colheita e armazenamento de sementes de coentro. Pesquisa Agropecuária Brasileira, v.41, n.12, p.1793-801, 2006.

NEERGAARD, P. Seed pathology. 2.ed. London: MacMillan Press, v.2, 1979. 1191p.

NUNES, M.U.C. et al. Introdução de tecnologias agroecológicas no sistema de produção de erva-doce em Sergipe. Revista Brasileira de Agroecologia, v.2, n.2, p.743-6, 2007.

PEDROSO, D.C. et al. Métodos de inoculação de Alternaria alternata e A. dauci em sementes de salsa e 
sua influência na qualidade fisiológica. Revista Brasileira de Sementes, v.32, n.3, p.79-85, 2010.

REIS, A. et al. Associação de Alternaria dauci e A. alternata com sementes de coentro e eficiência do tratamento químico. Horticultura Brasileira, v.24, p.10711, 2006.

SANTOS, J.P. Controle de pragas durante o armazenamento de milho. Sete Lagoas: EMBRAPACNPMS. 2006. 20p. (Circular técnica, 84).

SIMÕES, C.M.O. et al. Farmacognosia: da planta ao medicamento. Porto Alegre/Florianópolis: Editora da
UFRGS/Editora da UFSC, 2004.

SOUSA, L.A. et al. Sazonalidade dos ductos secretores e óleo essencial de Foeniculum vulgare var. vulgare Mill. (Apiaceae). Revista Brasileira de Farmacognosia, v.15, n.2, p.155-61, 2005.

WANDERLEY, P.A.; MARÇAL, L. Relatório anual de pesquisa do projeto erva-doce. Bananeiras, PB: UFPBASPTA, 1998. 12p. (Relatório de pesquisa).

TORRES, S.B. et al. Qualidade de sementes de maxixe armazenadas em diferentes embalagens e ambientes. Ciência Agrotécnica, v.26, n.3, p.539-44, 2002. 